\title{
The analysis of train reliability for the Taiwan High Speed Rail
}

\author{
J.-C. Jong ${ }^{1}$, T.-H. Lin ${ }^{1}$, C.-K. Lee ${ }^{2}$ \& H.-L. Hu ${ }^{3}$ \\ ${ }^{1}$ Civil \& Hydraulic Engineering Research Center, \\ Sinotech Engineering Consultants, Inc, Taiwan \\ ${ }^{2}$ Department of Marketing and Logistics, Southern Taiwan University, \\ Taiwan \\ ${ }^{3}$ Bureau of High Speed Rail, \\ Ministry of Transportation and Communications, Taiwan
}

\begin{abstract}
This study briefly reviews the development of the Taiwan High Speed Rail and analyzes its service reliability in terms of punctuality and average delay per train. The concept of risk management is also introduced in this paper to analyze the frequency and the severity of train delays caused by different kinds of accidents. According to the result of the analysis, signal and interlocking failures are the main reasons leading to train delays. Earthquakes and typhoons are also major threats to the system, even though the system tends toward stable. Based on the experiences of the Taiwan High Speed Rail, shortening the maintenance cycle can efficiently alleviate the problem of train delay caused by signal failures.
\end{abstract}

Keywords: High Speed Rail, train delay, risk management.

\section{Introduction}

On 1 October 1964, the world's first high-speed train commenced service on the Tokaido Shinkansen line between Tokyo and Osaka at a speed of $210 \mathrm{~km} / \mathrm{h}$. This date marks the start of the era of High Speed Rail (HSR). Despite the success of Shinkansen, the spread of HSR around the world was relatively slow. Seventeen years later, France launched a HSR service with a maximum speed of $270 \mathrm{~km} / \mathrm{h}$ between Paris and Lyon in 1981. Another seven years later, the world's third HSR was introduced in Italy. Afterwards, German and Spain also joined the club of HSR in 1991 and 1992, respectively [4]. 
In the late 20th century and the beginning of the $21 \mathrm{st}$ century, the development of HSR increased rapidly because of economic, environmental and external cost concerns, especially in the Far East [8]. In 2004, the Korea Railroad (Korail) opened its KTX between Seoul and Busan, using TGV technology [13]. Three years later, the Taiwan High Speed Rail (THSR), the first HSR outside Japan to adopt Shinkansen technology, was inaugurated to provide a high speed passenger service between Taipei and Kaohsiung at a maximal speed of 300 $\mathrm{km} / \mathrm{h}$. In 2008 and 2009, the Beijing-Tianjin HSR and the Wuhan-Guangzhou HSR were introduced in China. At present, the HSR has become a prevailing transportation mode and several projects are currently under development in different countries, including the High-Speed Intercity Passenger Rail (HSIPR) in the USA [3].

As it spreads around the world, HSR has been recognized as an energysaving, environment-friendly, and efficient mode of transportation [8]. People expect not only high-speed travel, but also safe and reliable service. After three years of operation, the THSR has carried more than 80 million passengers. Incidents leading to injuries and fatalities have never occurred to date. However, train delays are created sometimes. This study collected operation data from the Bureau of High Speed Rail (BOHSR), the supervisor and regulator of the THSR, to analyze the train reliability of the THSR. The study also introduced the concept of the risk management to analyze the frequency and the severity of train delays caused by different kinds of accidents. Through the proposed method, problems disturbing the normal operation of the THSR could be identified. The proposed methodology could be applied to other HSR or conventional railways for identifying, analyzing, and evaluating the risks of train delays.

\section{The Taiwan HSR project}

In the 1980s, Taiwan's economy was booming, especially in the western region. The growth of the economy led to increasing demands for intercity transportation. According to the investigation report in 1990 [5], the amount of trips between Taipei (the major city in the North of Taiwan) and Kaohsiung (the major city in the South of Taiwan) would increase by $84 \%$ until 2011 . The huge growth attracted much attention from the government to think about how to alleviate the congestion problem.

To overcome the capacity insufficiency problem and to achieve the goal of the "one-day living area" policy in Taiwan, a HSR system was finally selected from many alternatives. The THSR project was initially planned to be built by the public sector. Due to the increased public fiscal burdens, parliament withdrew the budget allocated to the THSR project and decided to have the project built by the private sector with a Build-Operate-Transfer (BOT) model [14]. This kind of infrastructure privatization model is spreading in many developing and developed countries under tight budgetary constraints [6]. With a construction value of $\$ 18$ billion, the THSR project was undoubtedly one of the most expensive concession transportation projects in the world at that time and perhaps even today. 
In September 1997, the Taiwan High Speed Rail Consortium was selected to be the best applicant for the BOT project. The Taiwan High Speed Rail Corporation (THSRC) was then incorporated in May 1998 as the concessionaire to build and operate the HSR service. The THSRC was licensed by the government to finance, construct, and operate the system for a period of 35 years and a concession for station area development for a period of 50 years [14]. The construction of the THSR started in 1999 and ended in 2006. The rail network links Taipei and Kaohsiung at a total length of 345 kilometers. Currently, eight stations are in operation, including Taipei, Banciao, Taoyuan, Hsinchu, Taichung, Chiayi, Tainan, and Zuoying (a district in Kaohsuing), as shown in Figure 1.

The THSRC imported 700T trains, a type of the Shinkansen rolling stock based on the 700 series, from Japan. It was the first time that the Shinkansen exported its system to a foreign country. The 700T train set has a distributed traction system formatted by 12 cars including nine power cars and three trailers. The passenger capacity of the $700 \mathrm{~T}$ train is 989 seats [11]. The designed maximum speed of the $700 \mathrm{~T}$ train is $315 \mathrm{~km} / \mathrm{h}$, but its commercial maximum speed is $300 \mathrm{~km} / \mathrm{h}$. The acceleration rate is $2.0 \mathrm{~km} / \mathrm{h} / \mathrm{s}$ and the deceleration rate is about $2.7 \mathrm{~km} / \mathrm{h} / \mathrm{s}$.

The whole network of the THSR is designed as double tracks. The maximum gradient is $35 \%$ and the minimum radius is 6,250 meters. The operation control center (OCC) is located at Taoyuan station. One maintenance base is situated near Hsinchu, and two depots are located in the center and south of Taiwan. The main workshop is located at Yenchao between Tainan and Kaohsiung. Normally, double-track operations are used, but the signaling system also provides the flexibility of single-line, bi-directional operations. In addition, the digital automatic train control (D-ATC) system is installed to ensure safety.

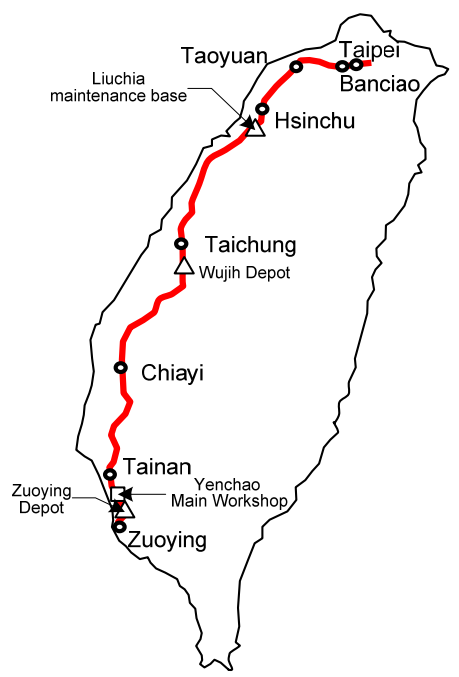

Figure 1: The route and stations of the THSR. 


\section{Train services and ridership}

Table 1 lists the stopping patterns and their associated journey time of the THSR. The stopping patterns combine non-stop, express, and local trains. At the beginning, the THSRC provided train services with many different kinds of stopping patterns. However, at present, almost all trains follow pattern B or E and very few adopt patterns F or G. Currently, pattern B is the fastest service between Taipei and Zuoying with a travel time of 96 minutes.

When the THSRC started commercial operations, only 38 train services were provided daily. Afterwards, more and more drivers completed training and the system tended toward stable. The THSRC constantly increased the number of daily services from 38 to 142 to achieve the request of the BOT contract until December 2008. After that, the THSRC reduced train frequency due to the economic depression. The trend of the number of daily services from January 2007 to March 2010 is displayed in Figure 2.

Table 1: The stopping patterns and the associated journey time of the THSR.

\begin{tabular}{|c|c|c|c|c|c|c|c|c|c|}
\hline Pattern & Taipei & Banciao & Taoyuan & Hsinchu & Taichung & Chiayi & Tainan & Zuoying & $\begin{array}{l}\text { Travel } \\
\text { Time } \\
(\mathrm{min})\end{array}$ \\
\hline A & & $\triangle$ & & & & & & 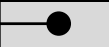 & 81 \\
\hline B & 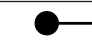 & $-\mathrm{O}$ & & & -0 & & & + & 96 \\
\hline C & 9 & -0 & & & $\mathrm{O}$ & -0 & -0 & 0 & 108 \\
\hline $\mathrm{D}$ & 0 & - & $\mathrm{O}-$ & - & 0 & & & 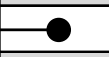 & 108 \\
\hline E & 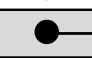 & -0 & $\mathrm{O}$ & -0 & -0 & $-\mathrm{O}$ & -0 & 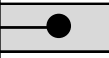 & 120 \\
\hline $\mathrm{F}$ & 0 & $\mathrm{O}-$ & - & -0 & 0 & & & & 57 \\
\hline G & & & & & ? & $-\mathrm{O}-$ & -0 & - & 60 \\
\hline
\end{tabular}

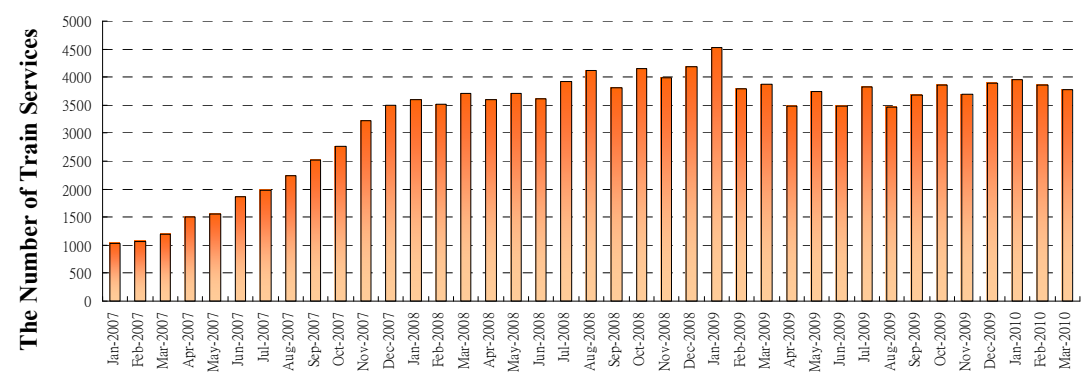

Figure 2: The trend of the number of daily train services. 
Since the fares of other modes in the Western corridor of Taiwan are cheaper than the THSR, except airlines, several marketing strategies were implemented to increase the seat utilization rate and the revenue of the THSRC. In addition to the half price promotion during the first two weeks at the beginning of commercial operations, the strategy of "non-reserved seats" has also been adopted since November 2007. The concept of non-reserved seats is that passengers need not book before riding; they can purchase tickets immediately after arriving stations, and then take any train without designated seats. The promotion provided more convenience for business travelers, and the price of non-reserved seats had a $20 \%$ discount during the first three months. The THSRC initially provided three cars of non-reserved seats per train, and this increased by one more in January 2008 to mitigate the crowded condition. After the three month period, the discount for non-reserved seats was adjusted several times until settling on a final value of $15 \%$. Additionally, the use of these tickets is now only permitted on weekdays, excluding Fridays and the days before holidays.

Another promotion that allowed $20 \%$ discounts on all types of tickets on weekdays was implemented from April to November 2008. During the period, the airlines between Taipei and Taichung, Taipei and Chiayi, Taipei and Tainan were cancelled. Only Taipei-Kaohsiung airlines survived and there remained three flights per week. Since November 2008, the THSRC has pushed a new program called "Two-Color Promotion". It was the first time that the THSR introduced the concept of revenue management. In this program, each train service was denoted by a color, either blue or orange. The blue indicates a $15 \%$ discount and the orange means a $35 \%$ discount. The THSRC has promoted this program to attract on-peak passengers to take off-peak trains.

Figures 3 and 4 depict the number of passengers and the seat utilization rate of the THSRC from January 2007 to March 2010. Generally speaking, the monthly ridership is approximately 2,500 3,000 thousand passengers and the seat utilization rate was approximately $40 \% \sim 50 \%$ last year. The influence of each promotion can also be observed roughly in these two figures.

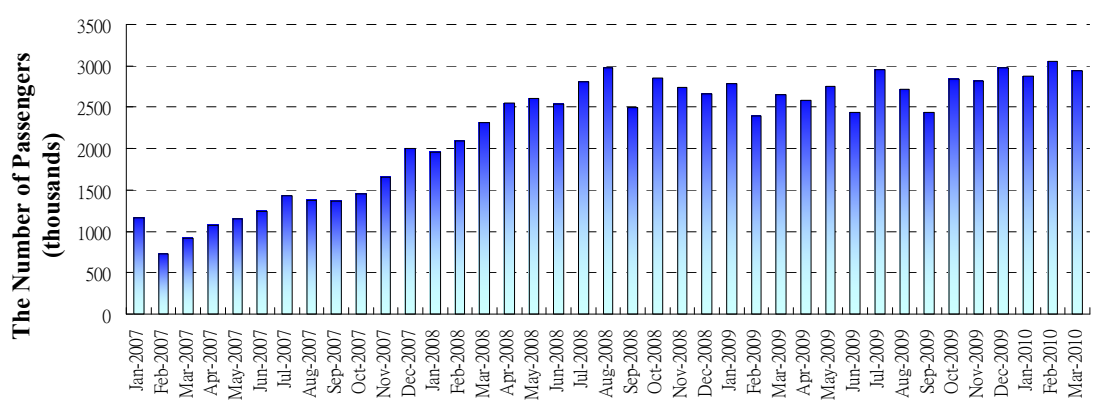

Figure 3: The number of passengers. 


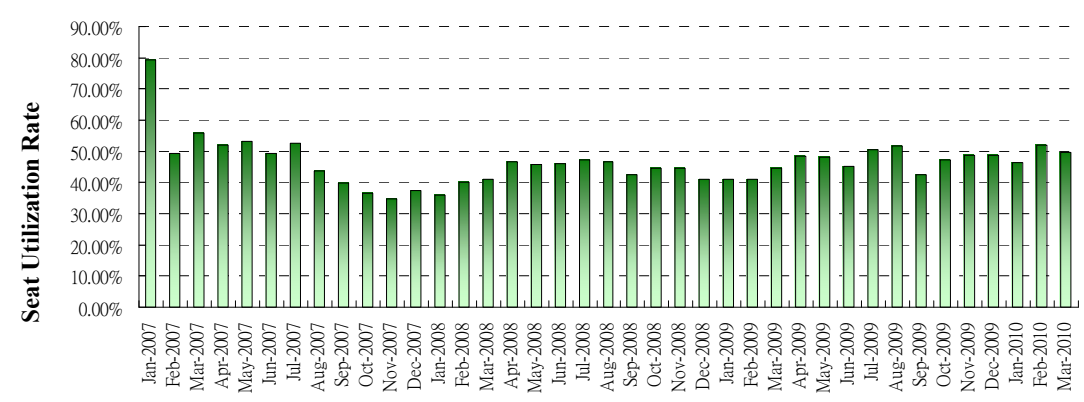

Figure 4: The seat utilization rate.

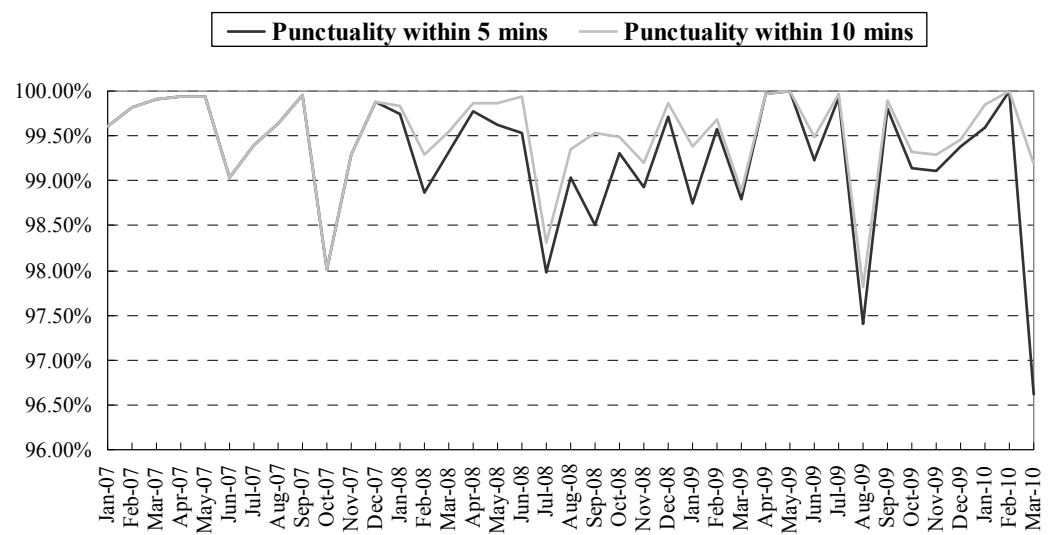

Figure 5: $\quad$ Monthly punctualities within 5 and 10 minutes.

\section{The analysis of punctuality and train delays}

Although the THSR has provided services for more than 80 million passengers since January 2007, no incident leading to injuries and fatalities has ever occurred. However, a few incidents causing train delays have indeed happened during the past three years. This section tries to analyze the punctuality and the train delays of the THSR. The concept of the risk management is also employed to analyze the frequency and the severity of train delays caused by different kinds of accidents.

\subsection{Trend of train punctuality}

Figure 5 shows the train punctualities of the THSRC within 5 and 10 minutes during the past three years. Since the THSRC did not report punctuality within 5 minutes to BOHSR in 2007, this data was not drawn. The figure indicates that monthly punctualities are almost higher than 98\%. In July 2008 and August 
2009, signal failures made punctuality drop below 98\%. In March 2010, an earthquake of magnitude 6.4 resulted in a minor train derailment. This earthquake caused damage to the train and running rails, but all passengers were safe. However, more than 20 trains were cancelled or adjusted to run with new stopping patterns after the earthquake. The earthquake led to a steep decline in punctuality to a value of $96.61 \%$, the lowest one since the THSRC's commercial operations.

\subsection{Trend of average delay}

The delays reported to BOHSR were presented by a frequency distribution with unequal delay interval, i.e., less than 5 minutes, between 5 and 10 minutes, between 10 and 30 minutes, between 30 and 60 minutes, and more than 60 minutes. The average train delay is approximated by the following equation:

$$
\bar{X}=\sum_{i=1}^{5} f_{i} M_{i} / n
$$

where: $\bar{X}=$ average train delay (minutes)

$f_{i}=$ the frequency of the $i$ th class

$M_{i}=$ the median of the $i$ th class (minutes); $M_{1}=0$ and $M_{5}=60$

$n=$ total train services

The above equation implies that trains with delays less than 5 minutes are considered to be punctual and that delays over 60 minutes are reset to 60 minutes for simplification. Besides, the medians of the other classes are used to represent the delay time for all trains in the classes. The approximation is not precise, but is a reasonable estimate of average delay. Figure 6 displays the average delay per train during the periods from January 2008 to March 2010. The results during 2007 are not shown in the figure since the number of delay less than 5 minutes is not recorded. The figure shows that the average delay per train ranges between 0 and 0.83 , demonstrating that the service of THSRC is very reliable.

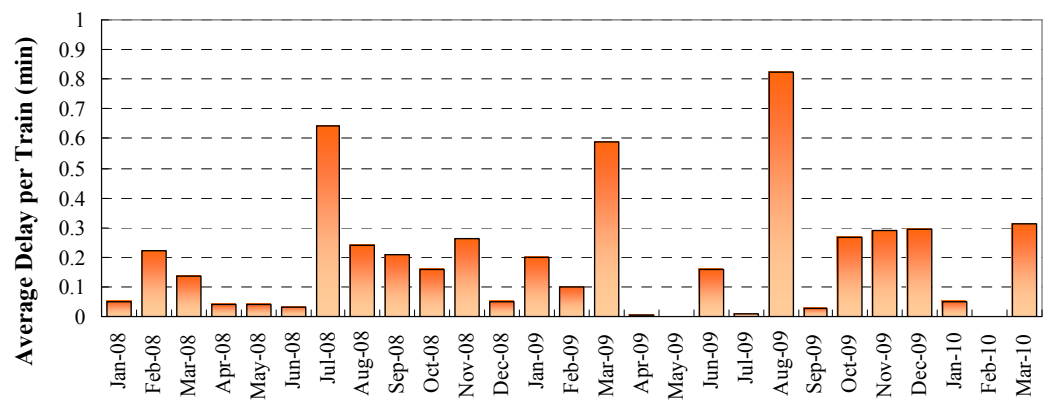

Figure 6: Average delay per train. 


\subsection{Delays caused by accidents}

Since BOHSR only requested THSRC to report specific accidents such as collisions, derailments, rolling stock failures, and the accidents causing train delays over thirty minutes, the data collected for this study were limited. Figure 7 presents the number of reported accidents per month from January 2007 to March 2010. The annual moving average (AMA) number of accidents normalized by 10 million train-kilometers is also marked in the figure. There has been a decreasing trend in the AMA over the past three years. In 2007, rolling stocks, tracks, and signal failures were the main reasons leading to train delays. As the operation of THSR gradually reaches to a stable condition, natural disasters such as earthquakes and typhoons become the major threats to train reliability nowadays. In addition, signal and interlocking failures are still potential hazards to reliability. The evidence from March 2009 showed that more than 3,000 minutes of train delays were resulted from only one signal failure.

Figure 8 uses another indicator, the total train delays caused by accidents, to represent the trend of reliability. It is easy to notice the contrast between Figure 7 and Figure 8. These two figures indicate that the frequency of accidents decreases, but the number of total train delays increases. That is because the number of train services has increased continuously in the last three years. Any accident might easily affect other trains and eventually cause train delays.

\subsection{The analysis of train delay risks}

The concept of risk has been widely applied to different disciplines. In railway industries, risk can be used to evaluate the threats to the success of a railway project, or the safety of a railway system. However, the applications of risk concept to train delays are seldom found in the literature. In this study, we tried to apply the concept of risk to evaluate the threats to train punctuality.

According to the "Operational Rules and Regulations of Railroads" stipulated by the Ministry of Transportation and Communications [10], railway accidents are classified into 17 categories: (1) train or rolling stock collision, (2) train or

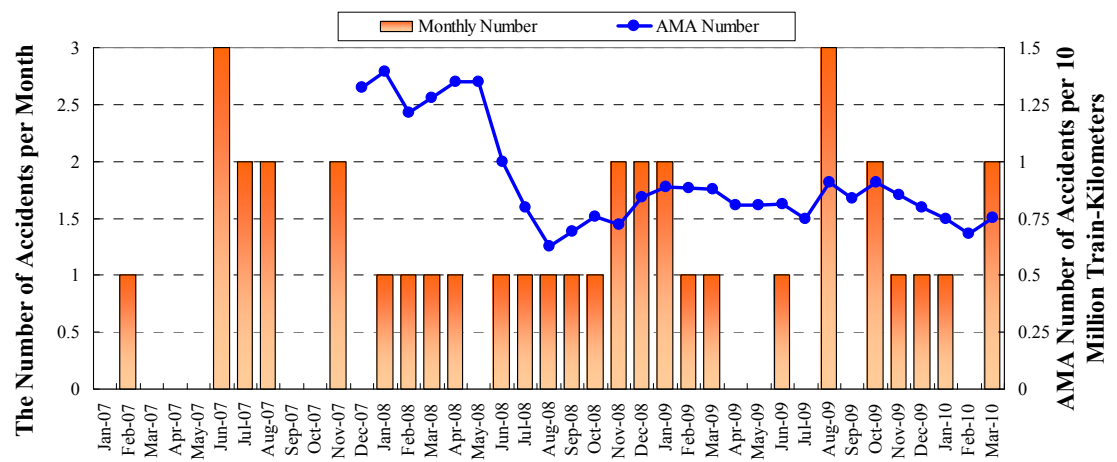

Figure 7: $\quad$ Trend of the number of accidents reported. 


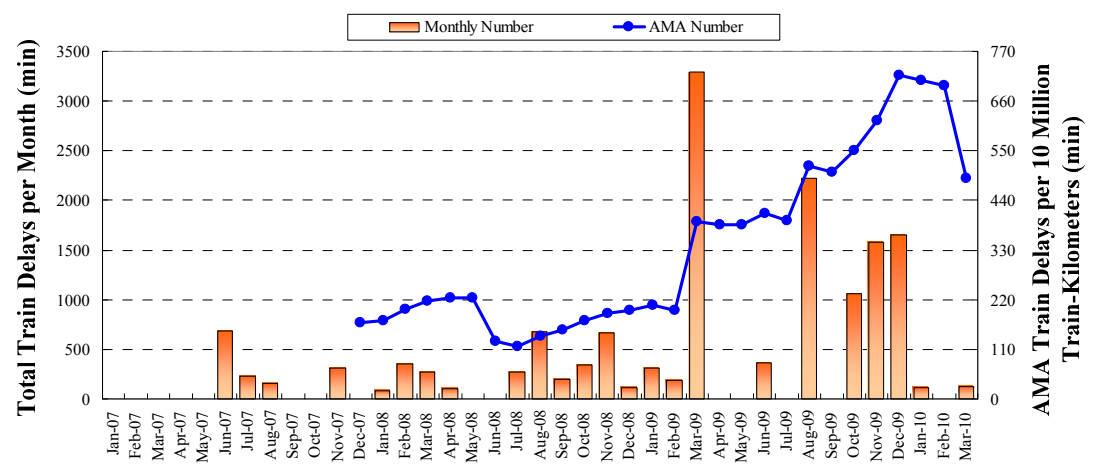

Figure 8: $\quad$ Trend of the total train delays caused by accidents.

rolling stock turnover, (3) train or rolling stock fire, (4) train or rolling stock derailment, (5) train or rolling stock separation, (6) train running into wrong track, (7) rolling stock runaway, (8) bumper stop collision, (9) false blocking, (10) rolling stock failure, (11) track or civil structure failure, (12) overhead catenary system (OCS) failure, (13) signal and interlocking system failure, (14) train forced to stop, (15) train stops outside home signal, (16) train delay, (17) fatality or injury. Note that the meanings of some accidents are not as clear as their titles. For examples, the accident of "train forced to stop" means that there are some obstacles on the line to obstruct train movement. Train delay represents accidents that are not included in categories (1) to (15) but lead to train delay. Likewise, fatality or injury denotes any other accidents that result in fatalities or injuries.

The frequency and the severity of an accident can be calculated by the following equations:

$$
\begin{gathered}
F_{k}=N_{k} / T K \\
S_{k}=D / N_{k}
\end{gathered}
$$

where: $F_{k}=$ the frequency of the $k$ th type of accident

$N_{k}=$ total number of the $k$ th type of accident per train-kilometer

$T K=$ total number of train-kilometers

$S_{k}=$ the severity of the $k$ th type of accident (minutes per accident)

$D=$ total amount of train delays (minutes)

Figure 9 shows the delay risk matrix of accidents. Since only eight kinds of accidents ever happened in the past, the matrix is only marked by eight symbols. It is obvious that the frequency of "signal and interlocking failure" is higher than the others. The severity of "other accidents leading to train delay" is also high. The reason is that earthquakes have occurred 5 times since 2007, causing almost 4,500 minutes of train delays. The severities of "train or rolling stock derailment" and "train or rolling stock collision" are relatively low since most of 
them happened in depots and did not disturb train operation except the derailment caused by an earthquake on March 2010.

Figure 10 shows the risk profile of train delays during the periods from January 2007 to March 2010, where the risk of an accident is calculated by multiplying the frequency with the severity of the accident. The figure demonstrates that "signal and interlocking failure" is undoubtedly the most serious threat to the reliability of THSR. "Other accidents leading to train delay" are also an important risk item, but their causes are diverse and complex. The top two accident types in the risk profile account for almost $80 \%$ of all train delays.

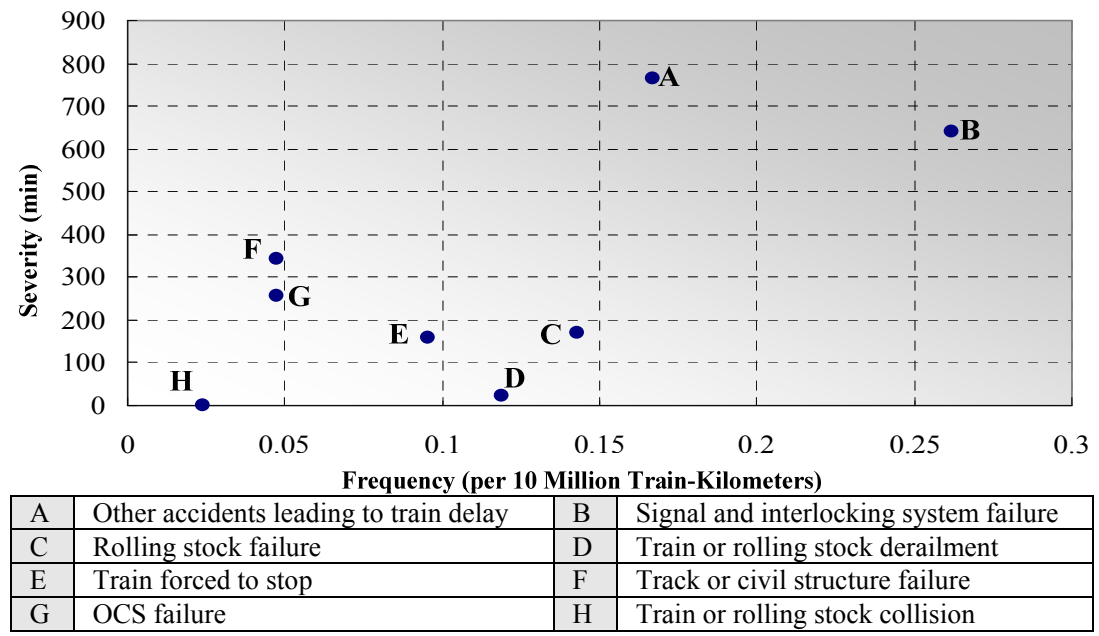

Figure 9: Delay risk matrix caused by accidents.

Train Delay Risk of Accident (min/10 Million Train Kilometers)

$\begin{array}{lllllllllll}0 & 20 & 40 & 60 & 80 & 100 & 120 & 140 & 160 & 180 & 200\end{array}$

\begin{tabular}{|c|c|c|c|c|c|}
\hline Signal and interlocking system failure & & & & & 167.422 \\
\hline Other accidents leading to train delay & & & & 127.603 & \\
\hline \multirow{2}{*}{ Rolling stock failure } & & 1 & 1 & 1 & \\
\hline & 24.292 & 1 & 1 & 1 & \\
\hline Track or civil structure failure & 16.337 & 1 & 1 & 1 & \\
\hline \multirow{2}{*}{ Train forced to stop } & 501 & I & 1 & 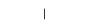 & \\
\hline & 15.242 & 1 & 1 & 1 & \\
\hline \multirow{2}{*}{ OCS failure } & $a=$ & 1 & 1 & 1 & \\
\hline & 12.265 & ( & (1) & (1) & \\
\hline \multirow{2}{*}{ Train or rolling stock derailment } & 0,61 & I & 1 & 1 & \\
\hline & 2.091 & 1 & 1 & 1 & \\
\hline Train or rolling stock collision & 0.000 & t & (1) & 1 & \\
\hline
\end{tabular}

Figure 10: Risk profile of train delays. 
Table 2: $\quad$ Comparison of reliability among different HSR systems in Asia.

\begin{tabular}{|l|l|l|}
\hline & Punctuality (within 5 min) & Average delay per train \\
\hline Shinkansen & $98.3 \%(2005)^{1}$ & $0.6 \mathrm{~min} /$ train $(2009)^{3}$ \\
\hline KTX & $94.1 \%(2008)^{2}$ & - \\
\hline THSR & $99.25 \%(2009)$ & $0.216 \mathrm{~min} /$ train $(2009)$ \\
\hline
\end{tabular}

1: The punctuality of Shinkansen was collected from Lee [7].

2: The punctuality of KTX was obtained from Lim [9].

3: The average delay per train for Shinkansen was collected from the data book of Central Japan Railway Company [1].

\section{The comparisons}

Table 2 lists the reliabilities of different HSR systems in Asia. It shows that THSR has the best performance in terms of both punctuality and average delay per train. However, it should be noted that the comparisons are not completely fair. That is because both train service frequency and operating distance affect service reliability. For examples, the service frequency (13 trains per hour) of the Tokaido Shinkansen from Tokyo to Shin-Osaka in the peak hour is much higher than that (five trains per hour) of THSR. The operating distance of KTX from Seoul to Busan is $412 \mathrm{~km}$, which is longer than the distance from Taipei to Kaoshiung of THSR $(345 \mathrm{~km})$. Even though the external conditions are too different to judge which system is better, THSR is undoubtedly a reliable system.

\section{Concluding remarks}

This study collected the punctuality and train delay data of THSR and applied risk concept to analyze the service reliability of the system. The result of the analysis shows that signal and interlocking failures are the main causes leading to train delays in THSR. Although the technologies of THSR were imported from Shinkansen, one of the most reliable systems in the world, the investigation reports of BOHSR pointed out that the reasons causing signal failures are various and undetermined. Even though the facts of failures are still unknown, THSRC has found that shortening maintenance cycle can efficiently mitigate the problems. Through the maintenance strategy, the punctuality has indeed increased after three signal failures in August 2009 until the earthquake happened in March 2010. We believe that the train delays caused by signal failures have been controlled by THSR, and the coming challenge will be how to ensure the safety and reliability while earthquakes and typhoons happen.

The proposed methodology to analyze and evaluate delay risks is very useful for operators to improve service reliability. From the resulting risk profile, operators could easily identify the most critical threats to service reliability and concentrate their efforts in mitigating the risks. However, that would require more detailed studies on mitigation measures for reducing the frequency or the severity of a threat to train reliability. 


\section{References}

[1] Central Japan Railway Company, Data Book 2009, Central Japan Railway Company, 2009.

[2] Department of Statistics, Monthly Statistics of Transportation and Communications Republic of China, Ministry of Transportation and Communications, 2010.

[3] Federal Railroad Administration (FRA), High-Speed Intercity Passenger Rail (HSIPR) Program; Notice, FRA, 2009.

[4] Givoni, M. "Development and Impact of the Modern High-speed Train: A Review", Transport Reviews, Vol. 26, No. 5, pp. 593-611, 2006.

[5] Institute of Transportation (IOT), The Feasibility Study of High Speed Rail on the Western Corridor of Taiwan, Ministry of Transportation and Communications, 1990.

[6] Kwak, Y. H., "Analyzing Asian Infrastructure Development Privatization Market", Journal of Construction Engineering and Management, Vol. 128, No. 2, pp. 110- 116, 2002.

[7] Lee, Y. S. "Achievements of KTX Project for the Past Year and Improvement Measures", Presented in the $5^{\text {th }}$ Congress \& Exhibition on High Speed Rail, 2005

[8] Lee, Y. S., A Study of the development and issues concerning High Speed Rail (HSR) - Working Paper, Transport Studies Unit - University of Oxford, 2007.

[9] Lim, B. O., "Innovations in Rolling Stock Maintenance Facilities", UIC $6^{\text {th }}$ World Congress on High Speed Railway, 2008.

[10] Ministry of Transportation and Communications (MOTC), Operational Rules and Regulations of Railroads, MOTC, 2008.

[11] Shima, T. "Taiwan High Speed Rail", Japan Railway \& Transport Review, No. 48, pp. 40-46, 2007.

[12] Taiwan High Speed Rail Corporation, ROD Incident and Accident Reporting and Investigation Procedure, Taiwan High Speed Rail, 2006.

[13] Takagi, R. High-Speed Railways : The Last 10 Years, Takagi, Japan Railways and Transport Review, No. 40, pp. 4-7, 2005.

[14] The official web site of Taiwan High Speed Rail Corporation, http://www.thsrc.com.tw/en/about/ab_comp.asp. 